\title{
Distribuição geográfica das espécies dos caramujos transmissores de Schistosoma mansoni no Estado de São Paulo
}

\author{
Geographic distribution of Schistosoma mansoni transmitter \\ snail species in State of São Paulo
}

\author{
Horacio Manuel Santana Teles ${ }^{1}$
}

\begin{abstract}
RESUMO
Os conhecimentos sobre a distribuição geográfica das espécies dos caramujos transmissores de Schistosoma mansoni são importantes para o controle e vigilância epidemiológica da esquistossomose mansônica. O estudo da situação no Estado de São Paulo, Brasil, demandou o exame dos caramujos de 8.771 lotes com amostras do gênero Biomphalaria, preservados em coleção de moluscos da Superintendência de Controle de Endemias. Os exames revelaram espécies dos caramujos transmissores da endemia em 3.712 lotes com 108.244 exemplares. As proporções foram de 225 (6\%) lotes de Biomphalaria glabrata (Say, 1818), 3.402 (91,7\%) de Biomphalaria tenagophila (d'Orbigny, 1835) e 85 (2,3\%) de Biomphalaria straminea (Dunker, 1848), cada espécie respectivamente com 8.002 (7,4\%), 88.068 (81,4\%) e 12.174 (11,2\%) exemplares. A distribuição geográfica de $\mathrm{B}$. glabrata $e \mathrm{~B}$. tenagophila apresenta criadouros muito agregados. No caso de $\mathrm{B}$. tenagophila, a maior compactação de criadouros coincide em regiões com elevados niveis de urbanização, muito conurbadas e poluídas. Já B. straminea, encontrada em criadouros das áreas de drenagem de todas as bacias hidrográficas, mostra uma disseminação mais rarefeita. Presume-se que devido às maiores facilidades do contato parasita/hospedeiros, os agregados de criadouros de B. glabrata $e$ B. tenagophila sejam propicios à preservação das áreas endêmicas de S. mansoni em São Paulo.
\end{abstract}

Palavras-chaves: Biomphalaria glabrata. B. tenagophila. B. straminea. Esquistossomose mansônica. Epidemiologia.

\begin{abstract}
A thorough knowledge of the geographic distribution of Schistosoma mansoni vector snails is indispensable for the control of Schistosoma mansoni schistosomiasis and its epidemiologic surveillance. From the water masses of the State of São Paulo (Brazil) 8,771 lots of snails - a total of 108,244 individuals of the genus Biomphalaria - were captured between 1982 and 2002. These specimens are now part of the malacological collection of (Superintendência de Controle de Endemias - São Paulo). According to species: Biomphalaria glabrata (Say, 1818), 225 lots (6\%) - 8,002 (7.4\%); specimens Biomphalaria tenagophila (d'Orbigny, 1835), 3,402 lots (91.7\%) - 88,068 (81.4\%) specimens and Biomphalaria straminea (Dunker, 1848), 85 lots (2.3\%) - 12,174 (11.2\%) specimens. The geographic distribution of $\mathrm{B}$. tenagophila and $\mathrm{B}$. glabrata breeding sites tends to be compact and their occupation of territory is clear-cut. B. tenagophila babitats characteristically show a tendency to cluster around municipalities with high levels of urbanization and organic pollution. The presence of $\mathrm{B}$. straminea is isolated in all hydrographic basins. This situation suggests that the persistence of schistosomiasis endemic areas in the State of São Paulo depends on the chance of host-parasite contacts resulting from the concentration of $\mathrm{B}$. tenagophila and B. glabrata breeding sites.
\end{abstract}

Key-words: Biomphalaria glabrata. B. tenagophila. B. straminea. Schistosomiasis mansoni. Epidemiology.

Apesar da disponibilidade de evidências experimentais que demonstram a suscetibilidade de outras espécies de Biomphalaria, no Brasil a transmissão de Schistosoma mansoni (Sambon, 1907) acontece em ambientes hídricos de água doce colonizados por caramujos planorbídeos das espécies
Biomphalaria glabrata (Say, 1818), Biomphalaria tenagophila (d'Orbigny, 1835) e Biomphalaria straminea (Dunker, 1848). Conquanto a presença dessas espécies seja essencial para a introdução e manutenção dos focos da esquistossomose mansônica, o sucesso da instalação e manutenção dos focos de

1. Superintendência de Controle de Endemias, São Paulo, SP.

Endereço para correspondência: Dr. Horacio Manuel Santana Teles. SUCEN. Rua Paula Souza, 166, 01027-000 São Paulo, SP.

Tel: 5511 3227-0622. Fax: 5511 3229-8292.

e-mail: horacio@sucen.sp.gov.br

Recebido para publicação em 8/11/2004

Aceito em 6/6/2005 
transmissão do helminto demanda a convergência de uma série de fatores biológicos e ambientais que, conforme a maior ou menor intensidade, determinam as diferenças das prevalências e da morbidade das infecções. A par de pormenores biológicos e ambientais, a transmissão do parasita também é favorecida pelas deficiências do saneamento básico. Assim, o controle eficiente da esquistossomose depende do desenvolvimento conjunto de medidas profiláticas, a exemplo do diagnóstico e tratamento dos portadores humanos, de obras de saneamento ambiental, de eventuais aplicações de moluscicidas e de mudanças de cunho social e econômico.

No Brasil, a esquistossomose ainda é um problema de saúde pública amplamente disseminado nas regiões sudeste e nordeste, enquanto nas regiões norte e sul, as áreas endêmicas apresentamse mais dispersas e isoladas. Ainda que as estimativas sobre o número de pessoas infecctadas e sujeitas à infecção sejam um assunto controverso, sempre superam a casa de milhões. Devido ao grande número de pessoas afetadas, e aos constantes deslocamentos da população em busca de melhores condições de vida, os portadores humanos do parasita são diagnosticados em todo o território nacional. Embora na maioria das vezes a doença passe despercebida, em áreas endêmicas, devido a maior chance da aquisição continuada de parasitas durante as exposições aos focos, os efeitos deletérios da esquistossomose manifestam-se com mais frequiência.

Dada a possibilidade do aparecimento de formas graves da doença, o problema exige o desenvolvimento de programas de controle e, em que pese a multiplicidade de fatores e determinantes epidemiológicos envolvidos na transmissão de S. mansoni, os conhecimentos permanente atualizados sobre a distribuição geográfica das espécies dos caramujos hospedeiros intermediários do parasita são imprescindíveis para 0 planejamento e desenvolvimento das ações de controle e profilaxia. 0 conhecimento da presença de espécies dos caramujos transmissores de $S$. mansoni servem de suporte às investigações que visam o esclarecimento da origem dos casos humanos diagnosticados e notificados, a partir de inquéritos coprológicos ou dos exames das rotinas da rede básica de saúde. Essa atividade é muito importante porque a notificação sucessiva de casos humanos supostamente autóctones em uma dada localidade ou município, facilita a descoberta e o combate aos focos do parasita.

Admitindo a importância do assunto, já no início da década de 60 , Corrêa e cols ${ }^{2}$ divulgaram os resultados de um estudo pioneiro sobre a ocorrência de espécies dos planorbídeos em São Paulo, posteriormente complementados por Piza e cols ${ }^{9}$. As informações fornecidas nesses estudos subsidiaram muitos dos avanços conseguidos no controle da esquistossomose em âmbito do território paulista, na época desenvolvido sob a responsabilidade da Campanha de Erradicação da Esquistossomose (CACEsq).

Esses conhecimentos foram úteis até a descrição Biomphalaria occidentalis Paraense, $1981^{7}$, espécie até então confundida por B. tenagophila. Diante da constatação da existência de criadouros dessa espécie em território paulista, seguida de informações que apontam B. occidentalis como uma espécie resistente à infecção por $S$. mansoni $i^{8}$, a Superintendência de Controle de Endemias (SUCEN) realizou um levantamento que visou a identificação das espécies da malacofauna de água doce, com o objetivo da atualização dos conhecimentos sobre a distribuição e ocorrência das espécies de interesse sanitário em São Paulo. Os trabalhos de campo e laboratório desse levantamento transcorreram por mais de três anos, encerrando-se em fins de 1986. Teles e Vaz ${ }^{18}$ e Teles ${ }^{15}{ }^{16}$ reportaram detalhes do empreendimento, cujos resultados permitiram 0 redimensionamento das áreas de risco da infecção por $S$. mansoni, tornando o controle e vigilância da endemia mais compatível com a realidade epidemiológica.

Daí em diante, as equipes de campo da SUCEN continuaram na execução de coletas de caramujos para as avaliações sobre a permanência e atividade dos focos da endemia, e de suporte das investigações epidemiológicas destinadas à classificação dos portadores humanos diagnosticados nos municípios paulistas. Outras coletas destinaram-se à vigilância em áreas de influência da construção e operação de barragens de hidrelétricas, bem como em outras obras realizadas nos cursos d'água. Essas atividades, além da descoberta de novas ocorrências das espécies dos caramujos transmissores da esquistossomose, possibilitaram a aquisição de informações importantes para a epidemiologia dessa endemia em São Paulo.

\section{MATERIAL E MÉTODOS}

Durante a etapa de base para a obtenção de informações das ocorrências das espécies dos caramujos presentes nas coleções hídricas de São Paulo, transcorrida de fins de 1982 a 1986, as equipes de campo da SUCEN realizaram coletas em coleções hídricas encontradas a cada perímetro de $100 \mathrm{~km}^{2}$. Se comprovada a presença de caramujos em pelo menos duas coleções hídricas distintas, as equipes deslocavam-se para os quadrantes adjacentes. A realização de pesquisas em seis sítios diferentes sem coleta de caramujos, também determinou a passagem das equipes para outro perímetro. 0 material coletado foi depositado em coleção mantida nas dependências do Laboratório de Malacologia da SUCEN.

Daí, até fins de 2002, as coletas de caramujos atenderam as demandas do programa de controle, para o acompanhamento ou descoberta de focos a partir das notificações da suspeita da existência de casos autóctones entre os portadores de $S$. mansoni diagnosticados em inquéritos coproscópicos ou durante as atividades de rotina da rede básica de saúde. Outra parte das coletas decorreu do desenvolvimento de estudos destinados à avaliação dos impactos ambientais da construção de hidrelétricas e de outros empreendimentos que exigem o represamento dos cursos d'água.

Para remessa a laboratório, os lotes de caramujos foram embalados em gaze seca. Depois de colocados em recipientes com água para a revitalização, os caramujos permaneceram sob iluminação artificial por 24 horas. A identificação das espécies demandou a observação de detalhes morfológicos das conchas e de órgãos do sistema excretor e genital, após extração e dissecção das partes moles pelas técnicas descritas por Deslandes $^{4}$ e Rey ${ }^{10}$. As observações sobre a infecção dos 
caramujos, caracterizadas pela eliminação de cercárias, se deram conforme o preconizado por Coutinho ${ }^{3}$, destacando que antes do esmagamento, pelo menos 10 exemplares de cada lote com amostras de Biomphalaria não detectadas anteriormente, foram separados para depósito em coleção. Para a preservação das amostras em coleção, as conchas passaram pela secagem em estufa. Depois da secagem, as conchas e partes moles, estas últimas imersas em líquido de Railliet \& Henry, constituíram os lotes de testemunho da ocorrência das espécies.

\section{RESULTADOS}

Dos 8.771 lotes com amostras de Biomphalaria preservados em coleção, os exames permitiram a identificação de espécies dos caramujos transmissores de S. mansoni em 3.712 (42,3\%) (Tabela 1). Nos $5.059(47,7 \%)$ lotes restantes os exames revelaram a presença das seguintes espécies: B. peregrina (d'Orbigny, 1835), B. schrammi (Crosse, 1846), B. intermedia Paraense \&Deslandes, 1961, B. oligoza Paraense, 1975 e B. occidentalis. Juntamente com as espécies envolvidas na transmissão de S. mansoni, esse é o elenco de espécies do gênero nas águas interiores do território paulista até o momento.

Tabela 1 - Lotes e exemplares de espécies dos caramujos hospedeiros intermediários de Schistosoma mansoni coletados de 1983 a 2002 nas coleções hídricas do Estado de São Paulo, Brasil.

\begin{tabular}{lrrcr}
\hline Espécies & Lotes & $\%$ & Exemplares & $\%$ \\
\hline B. glabrata & 225 & 6,0 & 8.002 & 7,4 \\
B. tenagophila & 3.402 & 91,7 & 88.068 & 81,4 \\
B. straminea & 85 & 2,3 & 12.174 & 11,2 \\
\hline Total & 3.712 & 100,0 & 108.244 & 100,0 \\
\hline
\end{tabular}

Em relação à origem, embora os lotes de $B$. glabrata, B. tenagophila e B. straminea procedessem de coleções hídricas do tipo lêntico ou lótico, as coletas foram sempre mais produtivas nos ambientes lênticos. Em coleções hídricas do tipo lótico, as coletas aconteceram em sítios remansosos. Dentre essas espécies de Biomphalaria, a média simples de caramujos coletados por sítio ou localidade foi 29,2 exemplares. Por espécie, a média foi de 35,6 para $B$. glabrata, de 25,9 para B. tenagophila e de 143,2 para B. straminea. Se o montante de exemplares coletados é uma expressão da abundância, embora B. straminea possua menor número de ocorrências, quando presente, coloniza as coleções hídricas em densidades populacionais mais elevadas que B. glabrata e B. tenagophila.

Na Figura 1, depreende-se que Biomphalaria glabrata possui a maior parte dos criadouros concentrados no quadrante das coordenadas geográficas $22^{\circ} 51^{\prime}$ e $23^{\circ} 95^{\prime} \mathrm{S}$ a $48^{\circ} 92^{\prime}$ e $50^{\circ} 85^{\prime} \mathrm{W}$. A área de distribuição natural da espécie abrange coleções hídricas dos municípios de Assis, Barão de Antonina, Campinas, Cândido Mota, Cerquilho, Coronel Macedo, Fartura, Florínea, Ibirarema, Ipauçu, Itaberá, Itaí, Itapeva, Itaporanga, Ourinhos, Palmital, Ribeirão do Sul, Riversul, Salto Grande, Santa Cruz do Rio Pardo, São Pedro do Turvo, Taguaí, Taquarituba e Xavantes, da bacia hidrográfica do Rio Paranapanema. Os municípios em negrito possuem focos de $S$. mansoni. Fora dessa área a espécie ocorre nos municípios de São Paulo (Capital),
Porto Feliz e Cerquilho, da bacia do Rio Tietê, e em Ribeirão Preto, em um ponto isolado entre os rios Mogi-Guaçu e Pardo.

Já a distribuição geográfica de $B$. tenagophila atinge divisas definidas pelas latitudes $20^{\circ} 63^{\prime}$ e $24^{\circ} 92^{\prime} \mathrm{S}$ e pelas longitudes $44^{\circ} 21^{\prime}$ e $52^{\circ} 12$ 'W. Conforme demonstra a Figura 2 , a espécie está presente por coleções hídricas de todas as bacias hidrográficas do perfil geográfico do estado. As maiores concentrações de criadouros da espécie acontecem nas vizinhanças dos cursos dos rios Paraíba do Sul, Ribeira de Iguape, do terço inicial do Tietê e em partes da zona litorânea. No mais, a disposição espacial dos criadouros é mais rarefeita, espraiada e ao acaso. A lista de municípios com ocorrências e focos de $S$. mansoni mantidos por B. tenagophila é a seguinte: Álvaro de Carvalho, Americana, Amparo, Anhembi, Aparecida, Apiaí, Araçatuba, Araçoiaba da Serra, Araraquara, Araras, Arujá, Atibaia, Avanhandava, Bananal, Bariri, Barra Bonita, Barueri, Bauru, Bebedouro, Biritiba Mirim, Bom Jesus dos Perdões, Boracéia, Botucatu, Brodósqui, Buri, Cabreúva, Caçapava, Cachoeira Paulista, Cafelândia, Caieiras, Caiuá, Cajamar, Campinas, Campo Limpo Paulista, Campos do Jordão, Cananéia, Capivari, Caraguatatuba, Carapicuíba, Castilho, Cerquilho, Charqueada, Conchas, Cordeirópolis, Cosmópolis, Cotia, Cruzeiro, Cubatão, Descalvado, Diadema, Dracena, Eldorado, Elias Fausto, Embu, Embu Guaçu, Espírito Santo do Pinhal, Fartura, Ferraz de Vasconcelos, Francisco Morato, Franco da Rocha, Gália, Garça, Gastão Vidigal, Getulina, Glicério, Guaiambé, Guarantã, Guararema, Guaratinguetá, Guarujá, Guarulhos, Holambra, Hortolândia, Iacri, Ibaté, Ibiúna, Igaraçu do Tietê, Iguape, Ilha Bela, Indaiatuba, Ipauçu, Iporanga, Iracemápolis, Itanhaém, Itapecerica da Serra, Itapetininga, Itapevi, Itapira, Itaporanga, Itapuí, Itaquaquecetuba, Itariri, Itatiba, Itu, Jaboticabal, Jacareí, Jacupiranga, Jaguariúna, Jambeiro, Jandira, Jarinu, Jaú, Júlio Mesquita, Jundiaí, Juquiá, Juquitiba, Laranjal Paulista, Lagoinha, Lavrinhas, Leme, Lençóis Paulista, Limeira, Lins, Lorena, Louveira, Macatuba, Mairinque, Mairiporã, Marília, Mauá, Mineiros do Tietê, Miracatu, Mococa, Mogi das Cruzes, Mogi Guaçu, Mogi Mirim, Mongaguá, Monte Alto, Monte Mor, Morungaba, Nova Odessa, Oriente, Osasco, Ourinhos, Panorama, Paraibuna, Pariquera Açu, Paulínia, Pederneiras, Pedreira, Pedro de Toledo, Penápolis, Pereiras, Peruíbe, Piedade, Pilar do Sul, Pindamonhangaba, Pinhalzinho, Piquete, Piracicaba, Piraju, Pirangi, Pirassununga, Poá, Pompéia, Porangaba, Porto Feliz, Praia Grande, Presidente Alves, Presidente Prudente, Promissão, Queluz, Rafard, Redenção da Serra, Registro, Ribeira, Ribeirão Pires, Ribeirão Preto, Rincão, Riversul, Rio Claro, Rio Grande da Serra, Roseira, Rubiácea, Salesópolis, Salto, Salto Grande, Salto de Pirapora, Santa Bárbara do Oeste, Santa Branca, Santa Cruz das Palmeiras, Santa Cruz do Rio Pardo, Santa Gertrudes, Santa Isabel, Santa Lúcia, Santana do Parnaíba, Santo Anastácio, Santo André, Santos, São Bernardo do Campo, São Caetano do Sul, São Carlos, São José dos Campos, São José do Rio Pardo, São Luiz do Paraitinga, São Manuel, São Miguel Arcanjo, São Paulo, São Pedro, São Roque, São Sebastião, São Simão, São Vicente, Sarapuí, Serrana, Sertãozinho, Sete Barras, Silveiras, Sorocaba, 


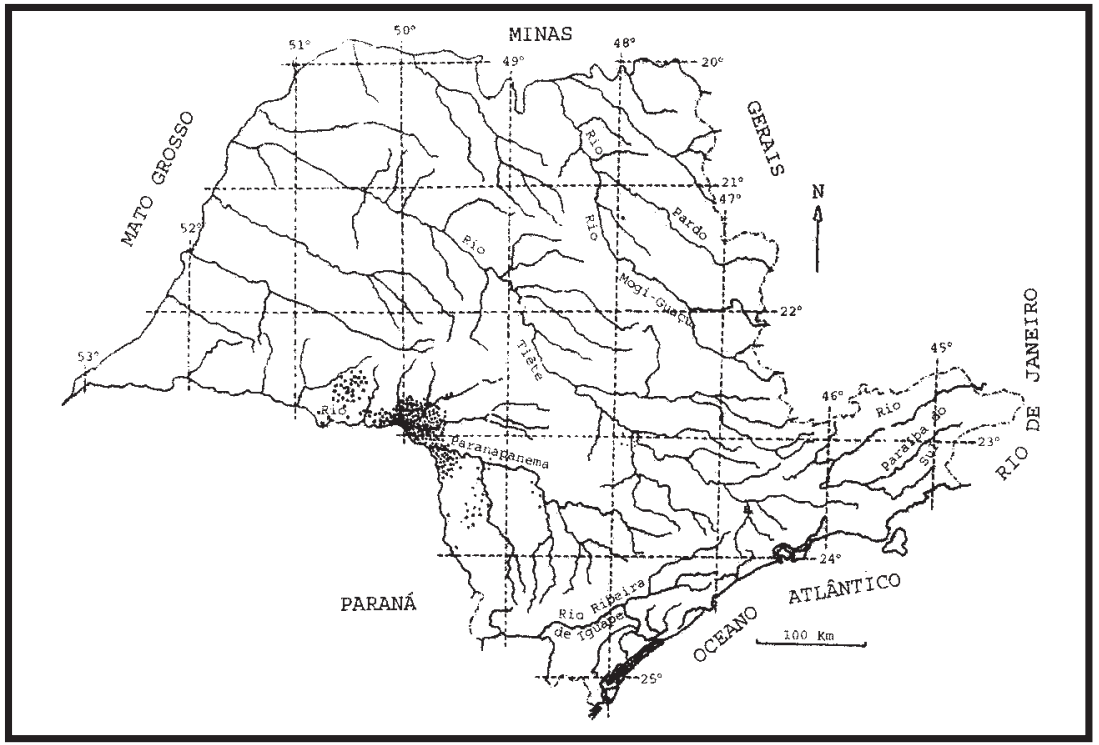

Figura 1 - Criadouros de Biomphalaria glabrata (Say, 1818) descobertos no Estado de São Paulo, Brasil, de 1983 a 2003.

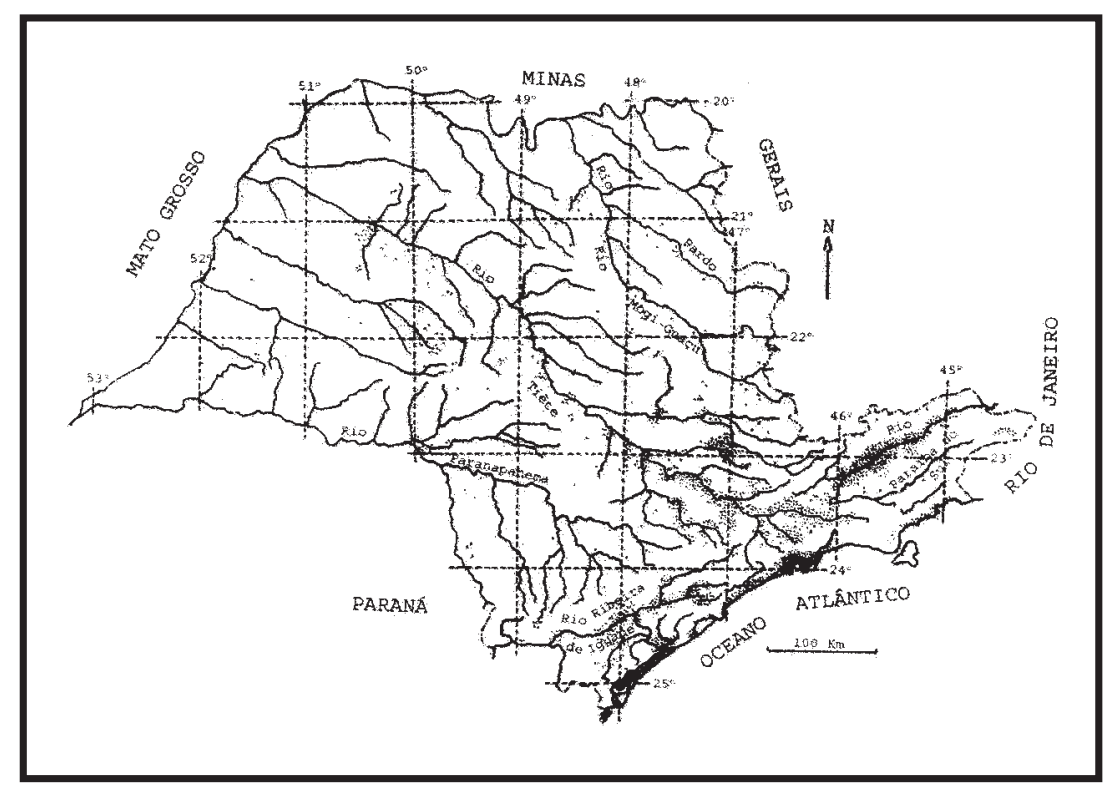

Figura 2 - Criadouros de Biomphalaria tenagophila (d'Orbigny, 1835) descobertos no Estado de São Paulo, Brasil, de 1983 a 2003.

Sumaré, Suzano, Taboão da Serra, Taguaí, Taiaçu, Taubaté, Tietê, Tremembé, Tupã, Ubatuba, Valinhos, Vargem Grande Paulista, Vargem Grande do Sul, Vera Cruz, Vinhedo, Votorantim e Xavantes.

0 mapeamento dos criadouros de $B$. straminea denota uma distribuição geográfica com limites de $20^{\circ} 20^{\prime}$ e $24^{\circ} 52^{\prime} S$ até $44^{\circ} 20^{\prime}$ e $51^{\circ} 83^{\prime}$ W (Figura 3). Na zona litorânea a presença de B. straminea restringe-se a município de Ilha Bela, da região do Litoral Norte. Com o mapeamento dos criadouros transparece um modelo de dispersão ao acaso, com posições em diversos quadrantes geográficos e hidrográficos. Na atualidade, a espécie possui criadouros nos municípios de Altair, Amparo, Andradina, Araçatuba, Araraquara, Araras, Avanhandava, Bananal, Barbosa, Barra Bonita, Bauru, Bebedouro, Botucatu, Caçapava, Campinas, Castilho, Cruzeiro, Fernandópolis, Gabriel Monteiro, Guaraçaí, Iepê, Igaratá, Ilha Bela, Ilha Solteira, Itapura, Iperó, Jaú, Lucélia, Neves Paulistas, Nova Granada, Ourinhos, Panorama, Paulo de Faria, Pereira Barreto, Pindamonhangaba, Presidente Prudente, Registro, Ribeirão Preto, Rio Claro, Rubinéia, Sales, Salto Grande, Santa Isabel, Santo Anastácio, Santo Antônio do Aracanguá, São José do Rio Preto, Serrana, Sertãozinho, Taboão da Serra, Taubaté e Tupi Paulista. 


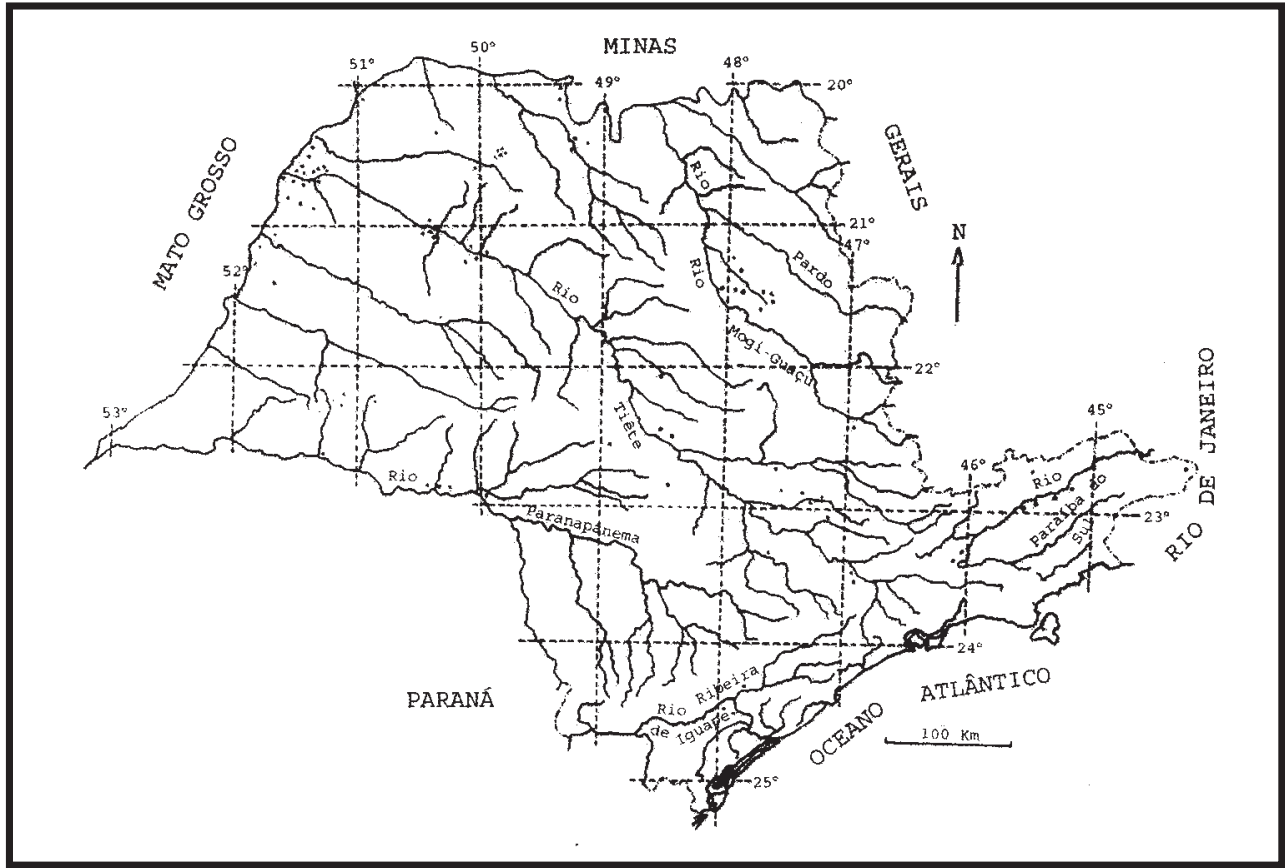

Figura 3 - Criadouros de Biomphalaria straminea (Dunker, 1848) descobertos no Estado de São Paulo, Brasil, de 1983 a 2003.

Os municípios destacados compõem as áreas endêmicas e de focos isolados de S. mansoni no Estado de São Paulo. Dessa maneira a transmissão associada à ocorrência de $B$. glabrata limita-se a focos existentes em municípios do trecho médio do Rio Paranapanema, enquanto $B$. tenagophila atua nos focos existentes nos vales do Rio Paraíba do Sul e Ribeira de Iguape, Baixada Santista, regiões metropolitanas da Grande São Paulo e Campinas, e isoladamente nos municípios de Bebedouro, Caraguatatuba e Ubatuba, os dois últimos da região do Litoral Norte.

\section{DISCUSSÃo}

A sequiência de coletas mantidas após o inquérito de base para a definição das áreas colonizadas pelas espécies dos caramujos hospedeiros intermediários de $S$. mansoni, além da descoberta de novas ocorrências, possibilitou a confirmação dos registros de B. glabrata realizados anteriormente por Piza e cols ${ }^{9}$ nos municípios de Florínea e Itaporanga. Considerando os resultados do estudo de Luz e cols ${ }^{6}$, percebe-se que os limites da área de ocorrência compacta de criadouros de B. glabrata em São Paulo consiste em um prolongamento de uma região mais ampla que abrange também o norte do Paraná, portanto que insere coleções hídricas de inúmeros municípios do trecho médio do Rio Paranapanema e tributários.

Em relação a $B$. tenagophila, foram assinaladas novas ocorrências nos municípios de Amparo, Araraquara, Atibaia, Campos de Jordão, Cedral, Cotia, Dracena, Holambra, Ilha Bela, Ipauçu, Jarinu, Jaú, Morungaba, Panorama, Presidente Prudente e Santo Anastácio, inexistentes na listagem divulgada por Teles ${ }^{16}$. Essas descobertas indicam sobretudo a dispersão continuada da espécie pela região oeste do território paulista, anteriormente limitada ao município de Caiuá. Investigações efetuadas nessa região sugerem que o incremento dos criadouros de B. tenagophila na região está diretamente relacionado à proliferação de estabelecimentos do tipo "pesque-pague". Nesse ramo dos negócios é comum a importação de alevinos e de peixes adultos produzidos em regiões colonizadas naturalmente por esta e outras espécies dos pulmonados de água doce transportados em recipientes que eventualmente carregam desovas e exemplares jovens dos caramujos. Depois de introduzidas nos tanques desse tipo de estabelecimento, é possível a invasão ambiental pelo escoamento dos tanques para manutenção.

Durante o período também foram identificados novos focos da esquistossomose mantidos por B. tenagophila nos municípios de Piquete, Holambra e Caraguatatuba, respectivamente das regiões do vale do Rio Paraíba do Sul, da área metropolitana de Campinas e do Litoral Norte. 0 encontro de caramujos infectados nos dois primeiros municípios deu-se em um contexto epidemiológico previsível, ou seja, em contiguidade a outros focos do parasita, ao contrário do evento de Caraguatatuba que sugere o potencial de transformação dessa região em uma nova área endêmica da esquistossomose. Teles e cols ${ }^{17}$ comentaram alguns dos condicionantes que demonstram a receptividade para a instalação de novos focos de $S$. mansoni na região litorânea.

Quanto a B. straminea, ficou constatada a existência de criadouros em Amparo, Pindamonhangaba, Taiaçu e Tremembé, e de Americana, Dracena, Ilha Bela, Mogi-Guaçu e Santo Anastácio, onde se observou a colonização de B. straminea em sintopia com Biomphalaria tenagophila. Essas descobertas complementam as ocorrências anteriormente descritas por Teles ${ }^{14} 15$ e confirmam 
a continuidade da dispersão ambiental de Biomphalaria straminea, sobretudo na bacia hidrográfica do Rio Tietê.

Em relação a $B$. glabrata e $B$. tenagophila, o levantamento mostra uma distribuição geográfica heterogênea, com criadouros espalhados ao acaso e concentrados em determinadas zonas, enquanto o modelo de dispersão de B. straminea apresenta-se unicamente ao acaso, porém com tendência à agregação em certas áreas. A par do maior número de ocorrências das duas primeiras espécies, a média de exemplares de $B$. straminea recolhidos por localidade foi superior, o que demonstra a abundância da espécie nos sítios de ocorrência. Nesse sentido, supõe-se que o número de exemplares coletados expresse a profusão da espécie na localidade, posto que as equipes de campo são sempre orientadas para a captura do maior número possível de caramujos durante a realização dos trabalhos de campo.

De outro lado, a presença de $B$. tenagophila e $B$. straminea por grandes amplitudes geográficas caracteriza a boa plasticidade e capacidade adaptativa dessas espécies, em que pesem as inevitáveis diferenças de certos parâmetros ambientais, como $\mathrm{pH}$, turbidez, dureza, entre outros, que tradicionalmente constituem fatores limitantes da dispersão e proliferação desse gênero dos organismos aquáticos. Em contraste, os limites de ocorrência de B. glabrata permaneceram estáveis, apesar da introdução e dispersão inicial da espécie em coleções hídricas de alguns municípios da bacia hidrográfica do Tietêt ${ }^{18}$.

No presente estágio dos conhecimentos sobre a distribuição geográfica das espécies dos caramujos transmissores e dos focos de $S$. mansoni, afora o aprimoramento das investigações destinadas à classificação dos casos de esquistossomose suspeitos de serem autóctones, existe a possibilidade da análise de alguns indicadores que permitem uma avaliação do potencial e da receptividade para a introdução e manutenção dos focos da doença em São Paulo.

De imediato, chama a atenção a coincidência das zonas mais intensamente colonizadas por B. glabrata e B. tenagophila com as áreas endêmicas de $S$. mansoni apresentadas pela SUCEN ${ }^{12} 13$. Essas áreas abrangem municípios das regiões dos vales dos rios Paraíba do Sul e Ribeira de Iguape, da Baixada Santista, Grande São Paulo e Campinas, onde a transmissão se mantém com a participação da segunda espécie, e do trecho médio do curso do Rio Paranapanema, com focos de B. glabrata. Outro fato interessante é a sobreposição das zonas de maiores densidades de ocorrências em regiões com elevados níveis de poluição e urbanização ${ }^{15}$. Diante dessas circunstâncias, parece patente que a introdução e manutenção dos focos de $S$. mansoni decorrem não somente das insuficiências do saneamento básico, da circulação de portadores humanos do parasita e da simples presença de caramujos suscetíveis. Tudo leva a crer que a formação e preservação das áreas endêmicas exigem também a disponibilidade de uma considerável agregação de coleções hídricas colonizadas pelos caramujos. A necessidade da convergência desses fatores justificaria o isolamento de alguns focos, a exemplo do que acontece no município de Bebedouro, bem como a preservação dos limites das áreas endêmicas, apesar dos esforços realizados no controle e redução dos riscos da infecção humana. Nesse sentido, é factível supor que as áreas endêmicas da esquistossomose permaneçam circunscritas aos limites atuais, posto que a distribuição de $B$. glabrata e B. tenagophila fora das áreas descritas, é mais espaçada e ao acaso, logo não reunindo as condições de transmissibilidade comuns às áreas endêmicas, o que implica a menor probabilidade de expansão dos focos para regiões indenes.

Ainda que $B$. glabrata e $B$. tenagophila continuem as espécies de maior significado epidemiológico para o controle e vigilância da esquistossomose no âmbito do estado, a participação regular de $B$. straminea na transmissão endêmica de $S$. mansoni, embora pareça remota no panorama atual, pode se modificar no futuro, devido à notável capacidade de adaptação dessa espécie à condições adversas. A descoberta de exemplares naturalmente infectados em uma coleção hídrica isolada do município de Cruzeiro, no Vale do Paraíba por Santos e cols ${ }^{14}$, pressupõe a préadaptação de $B$. straminea às raças de $S$. mansoni circulantes em São Paulo. Assim não é descartada a possibilidade que no futuro esta espécie ganhe importância epidemiológica, a exemplo do que acontece em outras regiões endêmicas brasileiras.

A par do controle da situação epidemiológica da esquistossomose em São Paulo, como evidenciam os dados coligidos pela SUCEN ${ }^{12}$ 13, nos limites das áreas endêmicas a doença ainda permanece um problema de saúde pública que exige atenção, sobretudo porque a permanência dos focos, em princípio coloca a possibilidade do desenvolvimento de formas graves da doença devido à possibilidade da aquisição sistemática de vermes. Diante disso, parece fundamental a necessidade de intervenções para a contenção da endemia, na forma de um programa que, afora a execução de atividades específicas, promova a integração dos diversos órgãos e instâncias com responsabilidade pelo desenvolvimento da profilaxia, incluindo o saneamento básico. Nas condições epidemiológicas atuais, presumese que a adoção de um modelo de programa de controle da esquistossomose que indique e proporcione o desenvolvimento de ações profiláticas integradas constitui a melhor estratégia para a continuidade da redução da prevalência e dos riscos da infecção humana no estado.

\section{AGRADECIMENTOS}

0 autor agradece ao Prof. Dr. Cláudio Santos Ferreira, do Instituto de Medicina Tropical da USP e à Dr. ${ }^{a}$ Maria Esther de Carvalho, da SUCEN, pelas inestimáveis sugestões e revisão do texto, e ao Dr. Roberto Mitsuyoshi Hiramoto, do Instituto Adolfo Lutz, pelo auxílio na confecção das figuras.

\section{REFERÊNCIAS BIBLIOGRÁFICAS}

1. Companhia de Tecnologia de Saneamento Ambiental. Qualidade das águas interiores do Estado de São Paulo, 2003. CESTESB, Secretaria do Meio Ambiente do Estado de São Paulo, www.cetesb.gov.br , 2004.

2. Corrêa RR, Piza JT, Ramos AS, Camargo LV. Planorbídeos do Estado de São Paulo. Sua relação com a esquistossomose (Pulmonata, Planorbidae). Arquivos de Higiene e Saúde Pública 27: 139-159, 1962.

3. Coutinho JO. Índice de infestação natural dos planorbídeos por cercárias de Schistosoma mansoni, na cidade de Salvador - Bahia. Anais da Faculdade de Medicina da Universidade de São Paulo 25: 23-53, 1950. 
4. Deslandes N. Técnica de dissecção e exame de planorbídeos. Revista do Serviço Especial de Saúde Pública 4: 371-382, 1951.

5. Fundação Sistema Estadual de Análise de Dados. Anuário Estatístico do Estado de São Paulo, 2002. SEADE, Secretaria de Economia e Planejamento do Estado de São Paulo, www.seade.gov.br, 2004.

6. Luz E, Silva SM, Carvalho AP, Castro N. Atualização da sistemática e distribuição geográfica dos planorbídeos (Gastropoda, Pulmonata) no Estado do Paraná (Brasil). Acta Biológica Paranaense 27: 39-55, 1998.

7. Paraense WL. Biomphalaria occidentalis sp. n. from South America (Mollusca, Basommatophora, Pulmonata). Memórias do Instituto Oswaldo Cruz 76: 199-211, 1981.

8. Paraense WL, Corrêa LR. Unsusceptibility of Biomphalaria occidentalis to infection with a strain of Schistosoma mansoni. Memórias do Instituto Oswaldo Cruz 77: 55-58, 1982.

9. Piza JT, Ramos AS, Moraes LVC, Correa RR, Takaku L, Pinto ACM. Carta Planorbídica do Estado de São Paulo. Secretaria de Estado da Saúde, Campanha de Combate à Esquistossomose (CACEsq) São Paulo, 1972.

10. Rey L. Técnicas de dissecção empregadas no estudo dos planorbídeos vetores da esquistossomose. Revista do Hospital das Clínicas 10: 293-297, 1955.

11. Santos L, Costa IB, Figueiredo CCSB, Altomani MAG. Primeiro encontro de Biomphalaria straminea Dunker, 1848, no município de Cruzeiro, Vale do Paraíba, Estado de São Paulo, naturalmente infectada por cercárias de Schistosoma mansoni. Revista do Instituto Adolfo Lutz 40: 165-166, 1980.

12. Superintendência de Controle de Endemias. Situação da Esquistossomose no Estado de São Paulo. SUCEN, Secretaria de Estado da Saúde do Estado de São Paulo, 1982.

13. Superintendência de Controle de Endemias. Programa de Controle da Esquistossomose (1981-1992). $2^{\circ}$ Encontro sobre Esquistossomose, Secretaria de Estado da Saúde do Estado de São Paulo (SUCEN), 1995.

14. Teles HMS. Aspectos ecológicos de Biomphalaria (Preston, 1910) (Basommatophora, Planorbidae) no Estado de São Paulo, Brasil. I. Sintopia. Ciência e Cultura 40: 374-379, 1988.

15. Teles HMS. Distribuição de Biomphalaria straminea ao Sul da Região Neotropical. Revista de Saúde Pública 30: 341-349, 1996.

16. Teles HMS. Distribuição de Biomphalaria tenagophila e B. occidentalis no Estado de São Paulo, Brasil. Revista de Saúde Pública 23: 244-253, 1989

17. Teles HMS, Hiramoto, RM, Oliveira JCN, Aveiro JA. Ocorrência de vetores da esquistossomose mansônica no litoral norte do Estado de São Paulo, Brasil. Cadernos de Saúde Pública 19: 1887-1891, 2003.

18. Teles HMS, Vaz JF. Distribuição de Biomphalaria glabrata (Say, 1818) (Pulmonata, Planorbidae) no Estado de São Paulo, Brasil. Revista de Saúde Pública 21: 508-512, 1987. 